\title{
钻孔灌注桩水下混凝土浇筑质量控制
}

\author{
张津滈 \\ 中铁建工集团有限公司深圳分公司 \\ DOI:10.18686/bd.v2i8.1556
}

[摘 要] 钻孔灌注桩是利用各种手段在地基土里面构建起许多桩孔, 在其中放入钢筋笼, 然后通过混凝土来实施灌注, 最终 得到的一种桩, 为了保障其施工质量, 本文阐述了钻孔灌注桩施工的工作原理以及钻孔灌注桩混凝土浇筑准备工作与钻孔 灌注桩水下混凝土浇筑要点, 对钻孔灌注桩水下混凝土浇筑质量控制进行了探讨分析。

[关键词] 钻孔灌注桩施工; 工作原理; 浇筑准备; 水下混凝土浇筑; 要点; 质量控制

钻孔灌注桩可有效降低建筑物的不均匀沉降, 因此其 被普遍运用在港口、桥梁以及高层建筑当中。为确保钻孔灌 注桩各个环节都能够顺利进行以及保证工程质量, 必须严 格控制钻孔灌注桩水下混凝土浇筑质量。

\section{1 钻孔灌注桩施工的工作原理分析}

钻孔灌注桩类型主要有冲击成孔灌注桩、正(反)循环钻 成孔灌注桩、潜水钻成孔灌注桩、长螺旋钻孔灌注桩和旋挖 成孔灌注桩等。钻孔灌注桩施工技术作为工程中广泛应用 的重要技术,其施工原理表现为:工程中,在备足原材料和清 孔之后,在混凝土中埋设导管的出料口,并利用进料口将混 凝土连续不断的注入桩孔之中, 再将导管提升的同时在混 凝土中埋设导管的进料口, 从而形成一定深度, 使得进料口 和出料口将产生强大的压力, 从而将再次浇灌的混凝土挤 人已浇混凝土之中, 从而提高钻孔灌注桩的坚固性和严实 性, 最后将最初浇灌混凝土的上部作为灌注桩的隔离顶层, 直至后续浇筑的混凝土被顶向灌注桩桩口。

\section{2 钻孔灌注桩混凝土浇筑准备工作的分析}

钻孔灌注桩混凝土浇筑准备工作

主要包括: (1)准备导管。在下面设置导管之前,一定要 先检测导管,查看导管有没有发生裂缝和漏洞现象; 丝口导 管有没有被损坏, 法兰导管其接头有没有老化, 是不是完好 的; 橡胶垫片有没有发生断裂, 必要情况下还要进行水压试 验, 保证在进行混凝土浇筑之前导管密封的足够严实。(2)准 备混凝土主要的一些材料。主要材料指的是粗细骨料和水 泥、水等这些材料。粗细骨料和水一定要进行试验, 按照设 计要求展开混凝土配合比的试验, 进而明确混凝土施工配 合比例, 同时跟工人互相展开技术交流。(3)验收上一道程 序。主要是对上一道程序进行验收, 确保孔低沉渣在设计的 合理范围之内。(4)准备浇注漏斗。通常情况下都是根据桩径 和导管的直径以及初灌量来确定漏斗大小, 为之后的转移 做准备,同时还要确保选择的漏斗能够达到初灌量的要求。 此外还要准备好隔水球。

\section{3 钻孔灌注桩水下混凝土浇筑要点的分析}

钻孔灌注桩最后一道工序就是水下混凝土浇筑, 该工 序直接关系着桩质量, 因此需要严格控制水下混凝土浇筑
要点,具体体现在:

3.1 导管安装要点

导管应该安装于孔中央,避免挂笼,且能保证整个桩身 的混凝土均匀。导管下放时必须按照水密性试验的编号依 此安装, 确保其严密性。导管下口距离孔底的高度一般控制 在 $30 \mathrm{~cm}$ 左右。导管安装完成后, 应该再次检查孔底沉渣厚 度及泥浆指标。

3.2 混凝土运输与拌制要点分析

混凝土灌注前必须备料充分, 修理施工便道, 确保畅通。 混凝土一般采用集中拌制, 利用混凝土输送车运输至现场 浇注。

主要表现为: (1)混凝土运输。在运输混凝土时, 应尽可 能防止在运输途中混凝土产生振动现象并掌握好时间, 如 果混凝土遭受了振动, 那么就会很容易让其离析, 如果运输 的时间比较长, 则又会大大降低混凝土的流动性能, 产生堵 管现象。(2)混凝土拌制。拌制混凝土的时候一定要准确根据 试验室之前确定好的配合比例进行拌制, 之后结合实际的 施工现场情况进一步确定好比例, 并根据最新的配合比例 进行配料, 如果条件允许的话最好运用电子计量系统, 正常 情况下使用磅秤计量也可以。但是计量的误差一定要控制 在: 黄砂上下相差不超过 $4 \%$; 水泥上下相差不超过 $2 \%$; 水 上下相差不超过 $1 \%$; 碎石上下相差不超过 $6 \%$; 水灰比的 误差控制在 0.1 以内。在搅拌时,千万记住要掌握好水灰比, 确保混凝土的粘聚性与和易性都达到最佳。

3.3 水下混凝土浇筑要点分析

主要体现在:(1)合理运用隔水球。使用比较广泛的隔水 球主要有木料、麻袋包木屑、混凝土和砂浆等等。运用剪球 法时,球外径一定要比导管内径小 2-3cm, 这样不仅方便隔 离导管内的泥浆和混凝土, 同时还能够让混凝土顺利的沿 着导管内壁進行流动, 不会发生堵管现象。目前把泥浆当做 隔水球比较普遍。(2)严格控制灌注速度。按照钻孔灌注桩水 下混凝土浇筑工艺提出的要求, 浇筑混凝土一定要保持连 续性, 这样才可以有效预防由于混凝土初凝所引起的断桩。 可是同时速度也不能过快, 速度太快很容易就会让导管过 深的被埋在混凝土里, 进而产生钢筋上浮和埋管等现象。(3) 
混凝土浇筑检测。第一、对连续浇筑混凝土到孔底之后的导 管埋藏深度进行有效测量,一定要使其大于 $1 \mathrm{~m}$, 其目的是为 了让混凝乳顺利的从导管当中流出来, 同时防止导管外泥 浆倒吸进导管中。在之后进行浇筑时,一定要实时观察混凝 土面上升情况和孔内导管其埋置状况,及时做好记录。在拆 除导管之前一定要遵守以下两点: 一个是导管埋到混凝土 内的深度要控制在 $1 \mathrm{~m}-6 \mathrm{~m}$ 之间; 另一个就是在提升导管时 不能太快, 不然的话会产生空心桩。第二、在混凝土面其上 升到跟钢筋笼底标高差不多相同的高度时, 还要注意: 放慢 灌注的速度, 确保钢筋笼有充足的时间沉到混凝土里; 拆除 导管之前, 要保证钢筋笼被埋在 $2 \mathrm{~m}$ 以上, 当导管进到钢筋 笼之后,则可以逐渐加快灌注的速度; 在灌注的时候要及时 选择一些混凝土样本当做试块加以养护, 主要是对桩混凝 土强度进行判断。

\section{4 钻孔灌注桩水下混凝土浇筑质量控制的分析}

4.1 钻孔灌注桩水下混凝土浇筑存在的质量问题分析 主要表现为:(1)缩颈问题。在钻孔灌注桩水下混凝土浇 筑施工过程中最常见的质量问题是缩颈。在桩体的浇筑过 程中,桩的四周围土体产生膨胀造成缩颈现象的发生。此类 情况发生,要及时采用优质的泥浆控制失水。如在成孔时发 生, 要加大泵量促使其迅速成孔, 在成孔完成后孔壁上会出 现一层泥皮, 这样孔壁即不会出现渗水现象也不会使膨胀 现象产生。(2)涌水问题。钻孔灌注桩施工过程中,在进行水 下混凝土浇筑时, 导管极易出现涌水的现象。究其原因, 主要 是钻孔灌注桩技术施工人员在工作的时候, 由于各种原因 而疏忽对导管的施工质量监管工作，使得导管内进人大量 的水,再加上压力的改变可能会导致导管的脱落,这些原因 导致了涌水问题的发生。(3)钢筋笼上浮问题。当成孔后进行 混凝土的浇注时, 会发生钢筋笼上浮的现象, 原因主要是在 清孔的过程中孔内残留下大量的泥块以及泥皮，这些泥块 以及泥皮随着混凝土浆面不断的上升, 导致泥块堵塞在钢 筋笼底部, 由于混凝土过小的流动, 而在混凝土中导管埋深 过大, 钢筋笼的质量问题有: 不直的和变形的钢筋笼, 钢筋笼 自身的重量太轻不能与孔口形成牢固的固定。

4.2 钻孔灌注桩水下混凝土浇筑质量控制的措施 主要体现在:(1)缩颈问题的质量控制。要解决钻孔灌注
桩水下混凝土浇筑施工过程中存在的缩颈问题, 要严格地 控制泥浆的比重并运用优质的泥浆降低钻孔的失水量。(2) 导管进水问题的质量控制。要解决钻孔灌注桩水下混凝土 浇筑施工过程中的涌水问题,首先是在施工之前,对导管进 行常规性地抽查,核查导管施工计划中是否有遗漏的部分; 其次是在施工的过程中,对于一些质量不过关的导管, 坚决 弃用,以保证施工的质量与水平。(3)钢筋笼上浮现象的质量 控制。第一、当钢筋笼的外径和套管内壁之间距离过小时, 很可能是套管内壁与䇚筋之间夹有粗骨料, 致使钢筋上浮 现象的产生。当此类情况发生时,解决的办法: 只要把筢筋 与套管内壁之间的距离加至粗骨料的最大尺寸的 2 倍即 可。第二、当混凝土灌注过多的钢筋笼时,加上导管的埋深 过大, 混凝土的上层会因浇注时间过长, 而产生初凝现象, 导 致表面出现硬壳, 这时导管的底端没有超过钢筋笼的底部, 在导管流出后的混凝土将迅速向上顶提升并带动钢筋笼往 上提升。如导管的埋深和已浇的混凝土的表面同等高度,再 提升导管后进行重新浇注,会使上浮现象得到解决。第三、 假如钢筋笼的初始位置过于高时, 混凝土的流量小, 在混凝 中的导管埋深过大, 混凝土把钢筋笼拖升。

\section{5 结束语}

由于钻孔灌注桩可以把上面的荷载传送到更深层更稳 固的土层内或者是岩石上面, 进而有效降低建筑物不均匀 沉降和基础沉降情况。并且由于现代工程建设对基础的要 求都普遍比较高, 而基础质量直接影响着工程上部构造安 全, 因此对钻孔灌注桩水下混凝土浇筑质量控制进行分析 具有重要意义。

参考文献:

[1]戚金.试论建筑地基施工中钻孔灌注桩的应用 [J]. 科学与财富,2017(13):212.

[2]]石否, 单春宇、钻孔灌注桩施工质量控制关键技术 的初步探讨[J].四川水泥,2015(12):189.

[3] 周发军.钻孔灌注桩水下混凝土浇筑技术质量控制 [J].住宅与房地产,2017(24):191。

[4]张金钻孔灌注桩水下混凝土浇筑技术的质量控制 [J].江西建材,2017(19):85. 